\title{
Cross-Sectional and Longitudinal Associations of Different Sedentary Behaviors with Cognitive Performance in Older Adults
}

\author{
Emmanuelle Kesse-Guyot ${ }^{1 *}$, Hélène Charreire ${ }^{1,2}$, Valentina A. Andreeva ${ }^{1}$, Mathilde Touvier ${ }^{1}$, \\ Serge Hercberg ${ }^{1,3}$, Pilar Galan ${ }^{1}$, Jean-Michel Oppert ${ }^{1,4}$
}

1 UMR Inserm U557, Inra U1125, Cnam, University Paris 13 Paris-cité-Sorbonne, Centre of Research on Human Nutrition Ile-de-France, Bobigny, France, 2 Paris-Est Créteil University, Department of Geography, Lab-Urba, Urbanism Institute of Paris, Paris, France, 3 Department of Public Health, Hôpital Avicenne, Bobigny, France, 4 Université Pierre et Marie Curie-Paris 6, Dept of Nutrition Pitié-Salpêtrière Hospital (AP-HP), Centre of Research on Human Nutrition lle-de-France, Paris, France

\begin{abstract}
Background: The deleterious health effects of sedentary behaviors, independent of physical activity, are increasingly being recognized. However, associations with cognitive performance are not known.

Purpose: To estimate the associations between different sedentary behaviors and cognitive performance in healthy older adults.

Methods: Computer use, time spent watching television (TV), time spent reading and habitual physical activity levels were self-reported twice (in 2001 and 2007) by participants in the SUpplémentation en Vitamines et MinérauX (SU.VI.MAX and SU.VI.MAX2) study. Cognitive performance was assessed at follow-up (in 2007-2009) via a battery of 6 neuropsychological tests used to derive verbal memory and executive functioning scores. Analyses (ANCOVA) were performed among 1425 men and 1154 women aged $65.6 \pm 4.5$ at the time of the neuropsychological evaluation. We estimated mean differences with $95 \%$ confidence intervals $(95 \% \mathrm{Cl})$ in cognitive performance across categories of each type of sedentary behavior.

Results: In multivariable cross-sectional models, compared to non-users, participants using the computer for $>1 \mathrm{~h} / \mathrm{day}$ displayed better verbal memory (mean difference $=1.86 ; 95 \% \mathrm{Cl}: 0.95,2.77$ ) and executive functioning (mean difference $=2.15 ; 95 \% \mathrm{Cl}: 1.22$, 3.08). A negative association was also observed between TV viewing and executive functioning. Additionally, participants who increased their computer use by more than 30 min between 2001 and 2007 showed better performance on both verbal memory (mean difference $=1.41 ; 95 \% \mathrm{Cl}: 0.55,2.27$ ) and executive functioning (mean difference $=1.41 ; 95 \% \mathrm{Cl}: 0.53,2.28$ ) compared to those who decreased their computer use during that period.
\end{abstract}

Conclusion: Specific sedentary behaviors are differentially associated with cognitive performance. In contrast to TV viewing, regular computer use may help maintain cognitive function during the aging process.

Clinical Trial Registration: clinicaltrial.gov (number NCT00272428).

Citation: Kesse-Guyot E, Charreire H, Andreeva VA, Touvier M, Hercberg S, et al. (2012) Cross-Sectional and Longitudinal Associations of Different Sedentary Behaviors with Cognitive Performance in Older Adults. PLoS ONE 7(10): e47831. doi:10.1371/journal.pone.0047831

Editor: Hemachandra Reddy, Oregon Health \& Science University, United States of America

Received June 20, 2012; Accepted September 17, 2012; Published October 17, 2012

Copyright: (c) 2012 Kesse-Guyot et al. This is an open-access article distributed under the terms of the Creative Commons Attribution License, which permits unrestricted use, distribution, and reproduction in any medium, provided the original author and source are credited.

Funding: This work was funded by the French National Research Agency ( ${ }^{\circ}$ ANR-05-PNRA-010), the French Ministry of Health, Médéric, Sodexo, Ipsen, MGEN and Pierre Fabre. Mederic and MGEN are French health insurance organizations, which are complementary to the National Health Insurance System. Ipsen and Pierre Fabre are private pharmaceutical companies. Sodexo, a food catering company, supported the study by organizing meetings between researchers and study participants. They financially supported the overall implementation of the research project. The funders had no role in study design, data collection and analysis, decision to publish, or preparation of the manuscript.

Competing Interests: The authors have declared that no competing interests exist.

* E-mail: e.kesse@uren.smbh.univ-paris13.fr

\section{Introduction}

Due to the overall aging of the population, a dramatic increase in age-related diseases is expected in the years to come, pointing to the need for prevention efforts capitalizing on environmental and behavioral strategies [1-3]. Findings from both observational and intervention studies are in favor of a beneficial effect of physical activity on preventing cognitive decline or the development of dementia [4-6]. However, most prevention-focused epidemiologic studies pertain to elderly or very old populations and there is a gap in knowledge of preclinical middle-age determinants. Current knowledge postulates that cognitive decline leading to Alzheimer's disease begins relatively early in life and progresses insidiously for decades before it is clinically expressed [7], arguing for the need to identify midlife factors associated with cognitive aging [8,9].

Parallel with physical activity, there is increasing interest in sedentary behavior as a complementary determinant of health outcomes [10-15]. Sedentary behavior refers to activities that do not increase energy expenditure above the resting level $[10,16]$. In 
a recent meta-analysis, television (TV) viewing, a typical sedentary behavior, was shown to be associated with increased risk of type 2 diabetes, cardiovascular disease and all-cause mortality [17], independent of habitual physical activity levels. Less is known about the health effects of other sedentary behaviors such as reading or computer use [11]. In addition, compared to the available evidence regarding sociodemographic and behavioral correlates of sedentary behaviors, only limited research has been conducted on the relationship between sedentary behaviors and cognitive outcomes [11]. Better knowledge of these associations is needed for identifying at-risk groups and for launching preventive actions [11].

Some studies point out the potential beneficial effect of engaging in cognitively stimulating leisure activities on cognitive aging [1831]. However, most of these studies have used composite frequency measure without considering the sedentary nature of such activities [18,21-27,29-31].

The aim of the present study was to assess whether different sedentary behaviors, including TV viewing, computer use and reading, would be differentially associated with indicators of cognitive function in healthy older adults.

\section{Materials and Methods}

\section{Study population}

The SU.VI.MAX (SUpplémentation en VItamines et Minéraux AntioXydants) study was a population-based, double-blind, placebo-controlled, randomized trial assessing the efficacy of a daily antioxidant supplementation on the incidence of cardiovascular disease and cancer [32,33]. The trial was launched in 1994 95 with a planned follow-up of 8 years (1994-2002). From the full SU.VI.MAX cohort $(\mathrm{N}=13,017)$, a total of 6,850 participants who had agreed to participate in a post-supplementation observational follow-up were recruited for the SU.VI.MAX 2 study (2007-2009) which included a neuropsychological evaluation [34].

\section{Ethics Statement}

The SU.VI.MAX and SU.VI.MAX 2 studies were conducted according to the guidelines laid down in the Declaration of Helsinki and were approved by the Ethics Committee for Studies with Human Subjects of the Paris-Cochin Hospital (CCPPRB n ${ }^{\circ}$ 706 and $\mathrm{n}^{\circ} 2364$, respectively) and the Comité National Informatique et Liberté (CNIL n ${ }^{\circ} 334641$ and $\mathrm{n}^{\circ}$ 907094, respectively). Written informed consent was obtained from all participants.

\section{Inclusion criteria}

Among the 6,850 adults included in the SU.VI.MAX 2 study (2007-2009), all cognitive tests were completed by a total of 4,447 individuals who were aged $45-60 \mathrm{y}$ at the start of the SU.VI.MAX trial in 1994. Among them, 2,835 participants had available data on sedentary behavior and physical activity from both 2001 and 2007. From that subsample, a total of 2,612 participants had available data for all covariables of interest. Finally, 33 participants who had been confined to bed for more than 1 month during the period covered by the physical activity questionnaires were excluded, leaving 2,579 participants for inclusion in the present analyses.

\section{Cognitive functioning assessment}

At the SU.VI.MAX 2 phase, the participants were invited to take part in a neuropsychological evaluation using validated tests regarding three memory domains (lexical-semantic, episodic and working) and mental flexibility. Lexical-semantic memory was assessed by verbal fluency tasks, including a phonemic fluency task (citing words beginning with the letter P) and a semantic fluency task (naming as many animals as possible). The score for each task was the number of correct words produced during a 2-min period [35]. Episodic memory was evaluated using the RI-48 test, which is a delayed cued recall test with a maximum score of 48 [36]. Working memory was assessed with the forward and backward digit span. One point was scored for each sequence repeated correctly, with a maximum score of 14 points for digit span forward as well as backward [37]. Mental flexibility was assessed through the Delis-Kaplan trail-making test (TMT), connecting numbers and letters alternating between the two series. The score was the time in seconds needed to complete the task [38].

\section{Sedentary behaviors and physical activity}

Sedentary behaviors and physical activity were assessed in 2001 and 2007 using a self-administered French version of the Modifiable Activity Questionnaire (MAQ) [39,40].

The original MAQ was designed to assess sedentary and physical activity during both leisure time and work over the past 12 months [41] and was the instrument used in the Diabetes Prevention Program [42]. The MAQ has been validated against energy expenditure measurements using the doubly-labeled water technique, and the test-retest properties of the questionnaire have been established [43]. Generally, participants were asked to report each leisure-time physical activity performed at least 10 times for at least $10 \mathrm{~min}$ per session over the past 12 months. The frequency and duration of each activity were also reported. For each reported physical activity, the number of hours per week was multiplied by its estimated metabolic cost expressed in metabolic equivalent tasks (MET) [44]. Then, a summary score was obtained expressed in MET-h per week. In the same questionnaire, participants were asked to report their average daily time spent watching $\mathrm{TV}$, using a computer, or reading, and each of these variables was expressed in min per day.

\section{Covariates}

At the start of the SU.VI.MAX trial, information on gender, date of birth, education and social position was collected. Retirement status was assessed at the time of each MAQ administration. At the SU.VI.MAX 2 phase, depressive symptoms were assessed using the French version of the Center for Epidemiologic Studies Depression Scale (CES-D) and the score was modeled as a covariate [45]. Tobacco use status (never, former, current smoker) and self-rated health status were collected through a self-administered questionnaire. Self-rated health status was assessed on a 5-point scale (excellent, good, fair, poor, very poor). During the clinical examination, weight was measured using an electronic scale, with participants wearing indoor clothing and no shoes. Height was measured under the same conditions with an electronic wall-mounted stadiometer. During the entire follow-up (1994-2009), the incidence of cardiovascular disease, hypertension and diabetes was documented [46].

\section{Statistical analysis}

Principal component analysis (PCA) was performed in order to yield summary measures accounting for the correlations among the cognitive scores, thereby maximizing the explained variance [47]. These summary scores were converted into $\mathrm{T}$ scores $($ mean $=50, \mathrm{SD}=10)$. Thus, a one-point difference in the test score corresponded to one-tenth of a SD difference. For each sedentary behavior, the original values (duration expressed in $\mathrm{min} /$ day) and change over time were categorized in three classes based on the respective distribution (tertiles or none/low/ high 
according to the median value). Body mass index (BMI) was calculated as the ratio of weight to squared height $\left(\mathrm{kg} / \mathrm{m}^{2}\right)$. Timedependent retirement status was computed as follows: retired at baseline, retired during follow-up, not retired at the end of followup.

Descriptive characteristics of the study sample are reported as mean (SD) or percentage. From the 13,017 participants included in SU.VI.MAX, those retained and those excluded from the present analyses were compared in order to assess potential selection bias. Reported P-values refer to the $\mathrm{chi}^{2}$ test or WilcoxonMann-Whitney test, as appropriate. Covariance analyses were used to estimate the difference in mean $(95 \%$ confidence interval, CI) cognitive scores across categories of sedentary behaviors as well as the 6-year change in sedentary behaviors using the lowest category as reference. $\mathrm{P}$ for trend was assessed, using linear contrast tests across categories. The initial model was adjusted only for the interval between sedentary behavior assessment and cognitive evaluation. The second model was adjusted for age (y), education (primary, secondary, university or equivalent), supplementation group (active or placebo), BMI, occupational category (unemployed, manual workers, employed, self-employed or farmers, managerial staff) and retirement status (yes/no). The third model was further adjusted for tobacco use status, BMI, depressive symptoms, history of hypertension (yes/no), history of diabetes (yes/no), and history of cardiovascular diseases (yes/no). The full final model was further adjusted for leisure-time physical activity (MET-h/week) and the remaining sedentary behaviors. The longitudinal models were similarly conducted except for an adjustment for the baseline score for each sedentary behavior. Retirement was considered a time-dependent covariable and the remaining sedentary behaviors (ie, those not modeled as the respective independent variable) in the full model were accounted for as change over time.

In an effort to assess the robustness of our results, we carried out sensitivity analyses after removing participants with the lowest cognitive performance scores (eg, below the education levelspecific tenth percentile), as these participants may have modified their physical activity or sedentary behaviors following changes in cognitive abilities. Interaction terms with gender and retirement status regarding sedentary behaviors were tested.

All tests were two-sided and type I error was set at 5\%. Statistical analyses were performed using SAS software (version 9.1, SAS Institute Inc, Cary, NC, USA).

\section{Results}

\section{Participants characteristics}

Baseline and follow-up descriptive characteristics of the participants included in the present study are presented in Table 1 . At the time of the cognitive assessment, mean age of the 2,179 included participants (1,425 men and 1,154 women) was $65.6(\mathrm{SD}=4.5) \mathrm{y}$ and $55 \%$ were male. More than two thirds of the participants rated their health as "good" or better. Few of the participants were smokers and the majority was retired.

Comparisons between included and excluded participants are shown (Table S1). Compared to included participants, those SU.VI.MAX participants who were excluded from the present analysis were younger, and therefore less likely to be retired, more often female (reflecting the initial SU.VI.MAX design) and smokers. They were also more active and spent more time engaged in sedentary behaviors. They also reported poorer general health and were more likely to report a history of diabetes and current depressive symptoms.
Table 1. Baseline and follow-up sociodemographic and behavioral characteristics of the participants $(\mathrm{N}=2,579)^{\mathrm{a}}$.

\begin{tabular}{|c|c|}
\hline & Mean (SD) or \% \\
\hline Male, \% & 55.3 \\
\hline Age (1994), $y^{a}$ & $52.2(4.6)$ \\
\hline Age (2007-2009), $y^{b}$ & $65.6(4.5)$ \\
\hline BMl, $\mathrm{kg} / \mathrm{m}^{2} \mathrm{~b}$ & $25.5(3.8)$ \\
\hline Intervention group, \% & 52.6 \\
\hline \multicolumn{2}{|l|}{ Education, $\%{ }^{a}$} \\
\hline Primary & 19.9 \\
\hline Secondary & 40.7 \\
\hline University & 39.4 \\
\hline \multicolumn{2}{|l|}{ Smoking status, $\%{ }^{\mathrm{b}}$} \\
\hline Never-smokers & 45.9 \\
\hline Former smokers & 43.4 \\
\hline Current smokers & 10.6 \\
\hline History of diabetes, \% & 6.8 \\
\hline History of hypertension, \% & 58.7 \\
\hline History of cardiovascular disease, \% & 4.7 \\
\hline Retired, \% ${ }^{\mathrm{b}}$ & 84.5 \\
\hline Depression score (CES-D) ${ }^{b}$ & $8.5(7.3)$ \\
\hline Leisure-time physical activity' MET-h/week ${ }^{b}$ & $26.5(27.2)$ \\
\hline Watching TV, $\min / d^{b}$ & $147.2(82.9)$ \\
\hline Computer use, $\min / \mathrm{d}^{\mathrm{b}}$ & $48.8(61.6)$ \\
\hline Reading, $\min / \mathrm{d}^{\mathrm{b}}$ & $73.0(54.9)$ \\
\hline \multicolumn{2}{|l|}{ General health status, $\%^{a}$} \\
\hline Excellent & 10.4 \\
\hline Good & 69.0 \\
\hline Fair & 19.4 \\
\hline Poor & 1.2 \\
\hline Very poor & 0.04 \\
\hline
\end{tabular}

CES-D, Center for Epidemiologic Studies Depression Scale.

${ }^{a}$ At baseline (1994).

${ }^{\mathrm{b}}$ At the SU.VI.MAX 2 examination (2007-2009).

doi:10.1371/journal.pone.0047831.t001

\section{Cognitive factor identification}

Two major cognitive patterns were extracted with PCA, accounting for $61 \%$ of the total initial variance. The first factor reflected semantic (factor loading $=0.80$ ) and phonemic fluency (factor loading $=0.65$ ) and the RI-48 cued recall task (factor loading $=0.76$ ), and it accounted for $42 \%$ of the total variance. The second factor accounted for $19 \%$ of the total variance and reflected the forward (factor loading $=0.85$ ) and backward (factor loading $=0.83$ ) digit span tasks and, to a lesser extent, the TMT (factor loading $=0.49$ ). These two factors were interpreted as reflecting "verbal memory" and "executive functioning," respectively, and were used in the subsequent analyses as the main variables regarding cognitive performance.

\section{Sedentary behaviors and cognitive performance}

No interaction between any of the sedentary behaviors and gender were detected (all $\mathrm{P}>0.05$ ) regarding cognitive function, thus analyses were conducted in the full sample. Cross-sectional associations between categories of the different sedentary behaviors (computer use, watching TV and reading) and indicators of 
cognitive performance are presented in Table 2. More time spent using the computer was associated with both better verbal memory and better executive functioning in crude and adjusted models. In the crude model, time spent watching TV was negatively associated with performance on both verbal memory and executive functioning. In the fully-adjusted cross-sectional model, more time spent watching TV remained associated with lower executive functioning scores. Reading was not associated with verbal memory. In addition, the association between more time spent reading and lower executive functioning scores did not remain significant in the fully adjusted models.

\section{Cross-time change in sedentary behaviors and cognitive performance}

The associations between the 6-year change in each sedentary behavior and cognitive function at follow-up are shown in Table 3. The increase in time spent using the computer was associated with better verbal memory and executive functioning, in crude and adjusted models. Changes in time spent watching TV or time spent reading were not associated with subsequent cognitive performance.

\section{Sensitivity analyses}

Cross-sectional and longitudinal analyses performed in a subsample $(\mathrm{N}=2,321)$ after removing participants with the lowest cognitive performance scores (eg, below the education levelspecific tenth percentile) showed similar, although weaker, associations (Table 4 and Table 5). The only notable difference was that the relationship between change in time spent using the computer and verbal memory performance was no longer detectable.

\section{Discussion}

In this population of older French adults, computer use was positively associated with a better performance in different cognitive domains, i.e. verbal memory and executive functioning, after controlling for a number of covariates including physical activity. In addition, the increase in time spent using the computer over 6 years was associated with better cognitive performance in both domains. A negative cross-sectional association was observed between TV viewing and executive functioning, which did not persist in the longitudinal models.

Our study provides new insights on the association between specific sedentary behaviors and cognitive function in healthy older adults.

\section{Strengths}

Some strengths of the study should be noted. In this population of aging adults, engagement in specific types of sedentary behavior was assessed at two time points using the same instrument. In turn, we employed a battery of sensitive neuropsychological tests known to limit floor or ceiling effects. Although residual confounding cannot be ruled out in observational studies, we were able to take into account a number of potential confounders, including educational level, health status, and presence of depressive symptoms, all of which have been found to be associated with sedentary behavior [11]. Finally, the present analyses included equal proportions of men and women.

\section{Sedentary behaviors and cognitive function}

A major finding of this study was the positive cross-sectional and longitudinal associations of the two dimensions of cognitive function with time spent using a computer. In turn, a negative (in cross-sectional models) or non-significant (in longitudinal models) relationship was found between cognitive function and

Table 2. Associations between time spent in sedentary behaviors (min/day) and cognitive function $(N=2,579)^{a}$.

\begin{tabular}{|c|c|c|c|c|c|c|c|}
\hline \multirow[b]{2}{*}{ Sedentary behavior } & & \multicolumn{3}{|l|}{ Verbal memory } & \multicolumn{3}{|l|}{ Executive functioning } \\
\hline & & T2 & T3 & $\mathbf{P}^{\mathbf{b}}$ & T2 & T3 & $\mathbf{P}^{\mathbf{b}}$ \\
\hline \multirow[t]{4}{*}{ Computer use } & Model $a^{c}$ & $2.96(2.00-3.92)$ & $2.51(1.59-3.44)$ & $<0.0001$ & $2.12(1.16-3.08)$ & $3.67(2.75-4.59)$ & $<0.0001$ \\
\hline & Model $b^{d}$ & $1.63(0.70-2.56)$ & $1.91(1.00-2.81)$ & $<0.0001$ & $0.64(-0.31-1.60)$ & $2.22(1.30-3.15)$ & $<0.0001$ \\
\hline & Model $c^{e}$ & $1.58(0.64-2.52)$ & $1.86(0.95-2.77)$ & $<0.0001$ & $0.60(-0.36-1.56)$ & $2.16(1.23-3.09)$ & $<0.0001$ \\
\hline & Model $d^{f}$ & $1.53(0.58-2.48)$ & $1.86(0.95-2.77)$ & $<0.0001$ & $0.47(-0.49-1.44)$ & $2.15(1.22-3.08)$ & $<0.0001$ \\
\hline \multirow[t]{4}{*}{ TV viewing } & Model $a^{c}$ & $-0.79(-1.76-0.18)$ & $-1.49(-2.42--0.56)$ & 0.002 & $-1.19(-2.15--0.22)$ & $-2.27(-3.19--1.34)$ & $<0.0001$ \\
\hline & Model $b^{d}$ & $-0.34(-1.25-0.58)$ & $-0.10(-1.00-0.79)$ & 0.82 & $-0.63(-1.56-0.31)$ & $-1.03(-1.94--0.11)$ & 0.03 \\
\hline & Model $c^{\mathrm{e}}$ & $-0.28(-1.20-0.63)$ & $-0.05(-0.95-0.86)$ & 0.92 & $-0.57(-1.50-0.37)$ & $-0.99(-1.92--0.06)$ & 0.04 \\
\hline & Model $d^{f}$ & $-0.28(-1.20-0.64)$ & $-0.06(-0.97-0.84)$ & 0.89 & $-0.50(-1.43-0.44)$ & $-1.02(-1.95--0.10)$ & 0.03 \\
\hline \multirow[t]{4}{*}{ Reading } & Model $a^{c}$ & $0.73(-0.21-1.68)$ & $0.57(-0.37-1.52)$ & 0.23 & $-0.76(-1.71-0.18)$ & $-0.96(-1.90--0.01)$ & 0.05 \\
\hline & Model $b^{d}$ & $0.56(-0.33-1.45)$ & $0.30(-0.61-1.20)$ & 0.52 & $-0.84(-1.75-0.07)$ & $-0.88(-1.81-0.05)$ & 0.06 \\
\hline & Model $c^{e}$ & $0.57(-0.32-1.47)$ & $0.26(-0.65-1.17)$ & 0.57 & $-0.85(-1.76-0.06)$ & $-0.95(-1.88--0.02)$ & 0.05 \\
\hline & Model $d^{f}$ & $0.54(-0.35-1.43)$ & $0.23(-0.68-1.14)$ & 0.62 & $-0.82(-1.73-0.09)$ & $-0.89(-1.81-0.04)$ & 0.06 \\
\hline
\end{tabular}

T2, T3: tertile of time spent in each of the sedentary behaviors.

Tertile 1 used as reference.

${ }^{a}$ Values are mean difference (95\% confidence interval) in cognitive scores, lowest category as reference.

${ }^{\mathrm{b}} \mathrm{P}$ for trend across categories.

cmodel a (crude): interval between sedentary behavior assessment and cognitive evaluation.

d model b: model a + age, gender, supplementation group, education, occupational categories, retirement status.

emodel c: model b + tobacco use status, BMI, CES-D score, general health status, history of cardiovascular diseases, diabetes and hypertension.

f model d: model c + leisure-time physical activity, remaining sedentary behaviors (TV, reading, computer according to main exposure).

doi:10.1371/journal.pone.0047831.t002 
Table 3. Associations between change in sedentary behaviors over 6 years and cognitive function $(N=2,579)$.

\begin{tabular}{|c|c|c|c|c|c|c|c|}
\hline \multirow[b]{2}{*}{ Change in sedentary behavior } & & \multicolumn{3}{|l|}{ Verbal memory } & \multicolumn{3}{|c|}{ Executive functioning } \\
\hline & & T2 & T3 & $\mathbf{P}^{\mathbf{b}}$ & T2 & T3 & $\mathbf{P}^{\mathbf{b}}$ \\
\hline \multirow[t]{4}{*}{$\Delta$ Computer use } & Model $a^{c}$ & $2.57(1.59-3.55)$ & $1.93(1.04-2.82)$ & $<0.0001$ & $2.16(1.18-3.14)$ & $2.46(1.57-3.34)$ & $<0.0001$ \\
\hline & Model $b^{d}$ & $1.42(0.48-2.37)$ & $1.47(0.62-2.32)$ & 0.001 & $1.10(0.13-2.06)$ & $1.44(0.56-2.31)$ & 0.001 \\
\hline & Model $c^{e}$ & $1.40(0.45-2.34)$ & $1.41(0.56-2.27)$ & 0.001 & $1.06(0.10-2.03)$ & $1.39(0.52-2.27)$ & 0.002 \\
\hline & Model $d^{f}$ & $1.34(0.38-2.29)$ & $1.41(0.55-2.27)$ & 0.001 & $0.95(-0.02-1.92)$ & $1.41(0.53-2.28)$ & 0.002 \\
\hline \multirow[t]{4}{*}{$\Delta \mathrm{TV}$ viewing } & Model $a^{c}$ & $0.26(-0.67-1.18)$ & $-0.65(-1.58-0.27)$ & 0.17 & $0.56(-0.38-1.51)$ & $-0.11(-1.06-0.84)$ & 0.82 \\
\hline & Model $b^{d}$ & $0.27(-0.66-1.19)$ & $-0.65(-1.59-0.28)$ & 0.17 & $0.10(-0.84-1.05)$ & $-0.32(-1.27-0.63)$ & 0.50 \\
\hline & Model $c^{e}$ & $0.31(-0.62-1.24)$ & $-0.64(-1.58-0.30)$ & 0.18 & $0.17(-0.78-1.11)$ & $-0.30(-1.25-0.66)$ & 0.54 \\
\hline & Model $d^{f}$ & $0.81(-0.13-1.76)$ & $0.27(-0.68-1.21)$ & 0.58 & $0.21(-0.73-1.15)$ & $-0.36(-1.32-0.59)$ & 0.46 \\
\hline \multirow[t]{4}{*}{$\Delta$ Reading } & Model $a^{c}$ & $-0.04(-0.99-0.90)$ & $-0.07(-1.02-0.88)$ & 0.89 & $0.14(-0.80-1.09)$ & $-0.16(-1.11-0.79)$ & 0.74 \\
\hline & Model $b^{d}$ & $0.13(-0.81-1.08)$ & $0.11(-0.83-1.05)$ & 0.82 & $-0.41(-1.38-0.56)$ & $-0.47(-1.43-0.49)$ & 0.34 \\
\hline & Model $c^{e}$ & $0.13(-0.82-1.08)$ & $0.06(-0.89-1.00)$ & 0.91 & $-0.41(-1.38-0.56)$ & $-0.59(-1.56-0.37)$ & 0.23 \\
\hline & Model $\mathrm{d}^{f}$ & $0.13(-0.82-1.08)$ & $0.04(-0.92-0.99)$ & 0.94 & $-0.36(-1.33-0.60)$ & $-0.61(-1.57-0.36)$ & 0.22 \\
\hline
\end{tabular}

T2, T3: tertile of change in time spent in each of the sedentary behaviors.

Tertile 1 used as reference.

${ }^{\mathrm{a} V}$ alues are mean difference ( $95 \%$ confidence interval) in cognitive scores, lowest category as reference.

${ }^{b} \mathrm{P}$ for trend across categories.

cmodel a (crude): interval between first sedentary behavior assessment and cognitive evaluation.

d model b: model a + age, gender, supplementation group, education, occupational categories, time-dependent retirement status + baseline value.

emodel c: model b + tobacco use status, BMI, CES-D score, general health status, history of cardiovascular diseases, diabetes and hypertension.

f model d: model c + delta of leisure-time physical activity, delta of remaining sedentary behaviors.

doi:10.1371/journal.pone.0047831.t003

TV viewing. The findings add to the presently scant literature on computer use and cognitive performance $[48,49]$. In fact, we could find no prior studies assessing both constructs simultaneously. In one previous US study [48], better cognitive performance, especially executive function, was observed among frequent computer users in a strictly cross-sectional design with adults aged

Table 4. Cross-sectional associations between engagement in sedentary behaviors (min/day) and cognitive function after removing participants with the lowest cognitive performance scores (eg, below the education level-specific tenth percentile) $(\mathrm{N}=2,321)^{\mathrm{a}}$.

\begin{tabular}{|c|c|c|c|c|c|c|c|}
\hline & & \multicolumn{3}{|l|}{ Verbal memory } & \multicolumn{3}{|c|}{ Executive functioning } \\
\hline \multicolumn{2}{|l|}{ Sedentary behavior } & T2 & T3 & $\mathbf{P}^{\mathbf{b}}$ & T2 & T3 & $\mathbf{P}^{\mathbf{b}}$ \\
\hline \multirow[t]{4}{*}{ Computer use } & Model $a^{c}$ & $2.01(1.05-2.98)$ & $1.44(0.52-2.37)$ & 0.002 & $1.77(0.77-2.76)$ & $3.03(2.08-3.98)$ & $<0.0001$ \\
\hline & Model $b^{d}$ & $0.78(-0.16-1.71)$ & $0.86(-0.04-1.77)$ & 0.06 & $0.29(-0.70-1.27)$ & $1.52(0.57-2.47)$ & 0.002 \\
\hline & Model $c^{e}$ & $0.78(-0.16-1.72)$ & $0.82(-0.09-1.73)$ & 0.08 & $0.25(-0.73-1.24)$ & $1.45(0.49-2.41)$ & 0.003 \\
\hline & Model $d^{f}$ & $0.78(-0.17-1.72)$ & $0.83(-0.09-1.74)$ & 0.08 & $0.17(-0.83-1.16)$ & $1.44(0.48-2.40)$ & 0.003 \\
\hline \multirow[t]{4}{*}{ TV viewing } & Model $a^{c}$ & $-0.74(-1.70-0.22)$ & $-1.29(-2.21-0.37)$ & 0.01 & $-1.06(-2.05-0.08)$ & $-2.23(-3.18-1.29)$ & $<0.0001$ \\
\hline & Model $b^{d}$ & $-0.21(-1.11-0.69)$ & $0.12(-0.77-1.01)$ & 0.79 & $-0.44(-1.39-0.51)$ & $-0.96(-1.89-0.02)$ & 0.05 \\
\hline & Model $c^{\mathrm{e}}$ & $-0.19(-1.10-0.72)$ & $0.09(-0.81-0.99)$ & 0.84 & $-0.40(-1.35-0.56)$ & $-0.96(-1.91-0.01)$ & 0.05 \\
\hline & Model $d^{f}$ & $-0.20(-1.11-0.70)$ & $0.08(-0.82-0.98)$ & 0.87 & $-0.35(-1.30-0.60)$ & $-0.98(-1.93-0.04)$ & 0.04 \\
\hline \multirow[t]{4}{*}{ Reading } & Model $a^{c}$ & $1.29(0.36-2.22)$ & $1.14(0.21-2.08)$ & 0.02 & $-0.46(-1.42-0.50)$ & $-0.58(-1.54-0.39)$ & 0.24 \\
\hline & Model $b^{d}$ & $1.06(0.19-1.94)$ & $0.81(-0.09-1.70)$ & 0.08 & $-0.52(-1.45-0.41)$ & $-0.51(-1.46-0.43)$ & 0.29 \\
\hline & Model $c^{\mathrm{e}}$ & $-0.52(-1.45-0.41)$ & $-0.57(-1.52-0.37)$ & 0.24 & $1.07(0.19-1.95)$ & $0.75(-0.15-1.65)$ & 0.10 \\
\hline & Model $d^{f}$ & $-0.52(-1.44-0.41)$ & $-0.56(-1.51-0.38)$ & 0.24 & $1.04(0.16-1.92)$ & $0.71(-0.19-1.61)$ & 0.12 \\
\hline
\end{tabular}

T2, T3: tertile of time spent in each of the sedentary behaviors.

Tertile 1 used as reference.

a Values are mean difference (95\% confidence interval) in cognitive scores, lowest category as reference.

${ }^{\mathrm{b}} \mathrm{P}$ for trend across categories.

cmodel a (crude): interval between sedentary behavior assessment and cognitive evaluation

${ }^{d}$ model b: model a + age, gender, supplementation group, education, occupational categories, retirement status.

emodel c: model b + tobacco use status, BMI, CES-D score, general health status, history of cardiovascular diseases, diabetes and hypertension.

fmodel d: model c + leisure-time physical activity, remaining sedentary behaviors (TV, reading, computer according to main exposure).

doi:10.1371/journal.pone.0047831.t004 
Table 5. Longitudinal associations between change in sedentary behaviors over 6 years and cognitive function after removing participants with the lowest cognitive performance scores (eg, below the education level-specific tenth percentile) $(\mathrm{N}=2,321)^{\mathrm{a}}$.

\begin{tabular}{|c|c|c|c|c|c|c|c|}
\hline & & \multicolumn{3}{|l|}{ Verbal memory } & \multicolumn{3}{|c|}{ Executive functioning } \\
\hline \multicolumn{2}{|l|}{ Change in sedentary behavior } & T2 & T3 & $\mathbf{P}^{\mathbf{b}}$ & T2 & T3 & $\mathbf{P}^{\mathbf{b}}$ \\
\hline \multirow[t]{4}{*}{$\Delta$ Computer use } & Model $a^{c}$ & $1.83(0.85-2.80)$ & $0.95(0.07-1.83)$ & 0.03 & $1.91(0.90-2.91)$ & $1.90(1.00-2.81)$ & $<0.0001$ \\
\hline & Model $b^{d}$ & $0.69(-0.24-1.63)$ & $0.56(-0.28-1.41)$ & 0.19 & $0.85(-0.14-1.84)$ & $0.88(-0.01-1.77)$ & 0.05 \\
\hline & Model ce & $0.72(-0.22-1.66)$ & $0.52(-0.33-1.37)$ & 0.23 & $0.83(-0.16-1.82)$ & $0.82(-0.07-1.72)$ & 0.07 \\
\hline & Model $d^{f}$ & $0.69(-0.25-1.64)$ & $0.52(-0.33-1.38)$ & 0.23 & $0.75(-0.25-1.74)$ & $0.83(-0.06-1.73)$ & 0.07 \\
\hline \multirow[t]{4}{*}{$\Delta \mathrm{TV}$ viewing } & Model $a^{c}$ & $0.81(-0.12-1.75)$ & $0.05(-0.90-1.00)$ & 0.91 & $0.27(-0.69-1.23)$ & $0.06(-0.91-1.04)$ & 0.90 \\
\hline & Model $b^{d}$ & $0.48(-0.43-1.39)$ & $-0.17(-1.09-0.75)$ & 0.71 & $-0.09(-1.05-0.87)$ & $-0.03(-1.01-0.94)$ & 0.95 \\
\hline & Model ce & $0.47(-0.45-1.38)$ & $-0.21(-1.14-0.72)$ & 0.66 & $-0.05(-1.01-0.91)$ & $-0.03(-1.01-0.94)$ & 0.95 \\
\hline & Model $d^{f}$ & $0.50(-0.42-1.42)$ & $-0.19(-1.12-0.75)$ & 0.69 & $-0.01(-0.97-0.95)$ & $-0.11(-1.09-0.87)$ & 0.83 \\
\hline \multirow[t]{4}{*}{$\Delta$ Reading } & Model $a^{c}$ & $0.11(-0.83-1.05)$ & $0.12(-0.82-1.05)$ & 0.81 & $0.29(-0.68-1.25)$ & $0.01(-0.96-0.97)$ & 0.99 \\
\hline & Model $b^{d}$ & $0.62(-0.31-1.56)$ & $0.57(-0.36-1.50)$ & 0.23 & $-0.13(-1.12-0.86)$ & $-0.15(-1.13-0.83)$ & 0.76 \\
\hline & Model ce & $0.62(-0.32-1.56)$ & $0.50(-0.43-1.43)$ & 0.29 & $-0.12(-1.10-0.87)$ & $-0.27(-1.25-0.72)$ & 0.60 \\
\hline & Model $d^{f}$ & $0.61(-0.33-1.55)$ & $0.47(-0.47-1.41)$ & 0.33 & $-0.11(-1.10-0.88)$ & $-0.31(-1.30-0.67)$ & 0.54 \\
\hline
\end{tabular}

T2, T3: tertile of change in time spent in each of the sedentary behaviors.

Tertile 1 used as reference.

${ }^{a}$ Values are mean difference ( $95 \%$ confidence interval) in cognitive scores, lowest category as reference.

${ }^{\mathrm{b}} \mathrm{P}$ for trend across categories.

cmodel a (crude): interval between first sedentary behavior assessment and cognitive evaluation.

${ }^{d}$ model b: model a + age, gender, supplementation group, education, occupational categories, time-dependent retirement status + baseline value.

e model c: model b + tobacco use status, BMI, CES-D score, general health status, history of cardiovascular diseases, diabetes and hypertension.

fmodel d: model c + delta of leisure-time physical activity, delta of remaining sedentary behaviors.

doi:10.1371/journal.pone.0047831.t005

32-84 years. However, in that study, the authors had assessed the frequency but not the average daily duration of computer use. In an earlier US report in adults [49], cognitive abilities (assessed through a standardized battery of 21 measures) were associated with computer use, but neither the frequency nor duration of use was specified. In the present study, sensitivity analyses showed that the association between computer use and verbal memory did not persist once individuals with low cognitive function scores were removed, arguing for further investigations regarding specific cognitive domains.

In most previous studies, sedentary behaviors have been grouped according to whether they were mainly mental, physical or social. For example, data on TV viewing have been previously modeled in a cluster of recreational, passive or cognitively stimulating activities [18,24,25,29-31], making it difficult to isolate a specific effect of this behavior. Consistent with our findings, TV viewing was positively associated with cognitive decline among Chinese subjects older than 55 years [28]. These authors suggested that engagement in such a passive activity could result from preclinical cognitive impairment. In line with this contention, the same research team also found that reading was associated with a reduced risk of cognitive impairment over a 5year follow-up. In our models, however, reading was not associated with cognitive function.

\section{Cognitively stimulating leisure activities and cognitive function}

The positive association between computer use and cognitive function is in line with previous research reporting a lower risk of dementia or cognitive decline among individuals with increased engagement in cognitively stimulating leisure activities [28]. Therefore, we can speculate that the mentally stimulating characteristics of some sedentary behaviors, such as computer use, may compensate for their relatively passive nature, regarding their impact on brain aging. The underlying mechanisms by which computer use may be related to cognitive function encompass the contribution of stimulating leisure activities to cognitive reserve on the one hand and the "use it or lose it" concept on the other hand. The cognitive reserve concept posits that some background factors (related to education, occupation, experience) may supply alternate capacities to cope with, or compensate for, neurologic damage thus delaying the clinical expression of dementia [50].

\section{Limitations}

Some limitations of this analysis need to be mentioned. First, the single assessment of cognitive performance did not allow evaluating causal relationships. In addition, participants with preclinical symptoms of cognitive decline may have discontinued some types of leisure activity and reverse causality cannot be ruled out. It should be noted, however, that after exclusion of participants with possible cognitive impairment, the associations with computer use remained significant. Second, data on sedentary behaviors were derived from self-reports, which may have led to an underestimation of such behaviors and/or to a misclassification bias. In particular, we did not have information on the purposes of using the computer (eg, browsing the Internet, reading, playing games, blogging, etc.). Indeed, computer use could be an active or a passive occupation. Similarly, data on the types of reading material (textbooks, fiction, newspapers, comics, trade magazines, etc.) were not available which may partly explain the absence of an association with cognitive function. An objective measurement of sedentary behavior would require the use of movement counters such as accelerometers [51], although this method does not allow the assessment of the type of sedentary behavior performed. Third, we assessed sedentary behaviors only during leisure time because over three-quarters of the participants 
in our sample were retired. Finally, caution is needed when estimating the external validity of our findings as the participants were health-conscious, well-educated volunteers initially involved in a long-term nutritional intervention. This may have led to homogeneity in lifestyles and in cognitive profiles, reducing the probability of detecting significant associations. Furthermore, the analyzed sample may be considered as overselected because participants having all available data may have been particularly compliant, as shown by the comparison between included and excluded participants. These results should therefore be confirmed in other populations.

\section{Conclusion}

In conclusion, the results of this study, carried out in healthy older persons, suggest that sedentary behaviors may not be equal in their impact on cognitive performance, depending on their level of cognitive stimulation. Computer use, a widespread occupation in technology-based societies, may be beneficial in maintaining cognitive function, especially verbal memory and executive functioning. Nonetheless, the potentially beneficial impact of computer use does not preclude a harmful effect in case of abuse and this specific effect should be investigated in ad-hoc studies. Widespread computer access, however, may become a public health challenge with regard to the maintenance of cognitive performance during aging. Further investigations in different

\section{References}

1. Middleton LE, Yaffe K (2009) Promising strategies for the prevention of dementia. Arch Neurol 66: 1210-1215.

2. Plassman BL, Williams JW Jr., Burke JR, Holsinger T, Benjamin S (2010) Systematic review: factors associated with risk for and possible prevention of cognitive decline in later life. Ann Intern Med 153: 182-193.

3. Coley N, Andrieu S, Gardette V, Gillette-Guyonnet S, Sanz C, et al. (2008) Dementia prevention: methodological explanations for inconsistent results. Epidemiol Rev 30: 35-66.

4. Sofi F, Valecchi D, Bacci D, Abbate R, Gensini GF, et al. (2011) Physical activity and risk of cognitive decline: a meta-analysis of prospective studies. J Intern Med 269: $107-117$.

5. Jedrziewski MK, Lee VM, Trojanowski JQ (2007) Physical activity and cognitive health. Alzheimers Dement 3: 98-108.

6. Rockwood K, Middleton L (2007) Physical activity and the maintenance of cognitive function. Alzheimers Dement 3: S38-S44.

7. Mortimer JA, Borenstein AR, Gosche KM, Snowdon DA (2005) Very early detection of Alzheimer neuropathology and the role of brain reserve in modifying its clinical expression. J Geriatr Psychiatry Neurol 18: 218-223.

8. Singh-Manoux A, Kivimaki M (2010) The importance of cognitive aging for understanding dementia. Age (Dordr) 32: 509-512.

9. Hughes T, Ganguli M (2010) Modifiable midlife risk factors for late-life dementia. Rev Neurol 51: 259-262.

10. Biddle SJ (2007) Sedentary behavior. Am J Prev Med 33: 502-504.

11. Rhodes RE, Mark RS, Temmel CP (2012) Adult sedentary behavior: a systematic review. Am J Prev Med 42: e3-28.

12. Thorp AA, Owen N, Neuhaus M, Dunstan DW (2011) Sedentary behaviors and subsequent health outcomes in adults a systematic review of longitudinal studies, 1996-2011. Am J Prev Med 41: 207-215.

13. Proper KI, Singh AS, van MW, Chinapaw MJ (2011) Sedentary behaviors and health outcomes among adults: a systematic review of prospective studies. Am J Prev Med 40: 174-182.

14. Owen N, Sugiyama T, Eakin EE, Gardiner PA, Tremblay MS, et al. (2011) Adults' sedentary behavior determinants and interventions. Am J Prev Med 41: $189-196$.

15. Edwardson CL, Gorely T, Davies MJ, Gray LJ, Khunti K, et al. (2012) Association of sedentary behaviour with metabolic syndrome: a meta-analysis. PLoS One 7: e34916.

16. Pate RR, O'Neill JR, Lobelo F (2008) The evolving definition of "sedentary". Exerc Sport Sci Rev 36: 173-178.

17. Grontved A, Hu FB (2011) Television viewing and risk of type 2 diabetes, cardiovascular disease, and all-cause mortality: a meta-analysis. JAMA 305: 2448-2455.

18. Wilson RS, Barnes LL, Aggarwal NT, Boyle PA, Hebert LE, et al. (2010) Cognitive activity and the cognitive morbidity of Alzheimer disease. Neurology 75: $990-996$.

19. Singh-Manoux A, Richards M, Marmot M (2003) Leisure activities and cognitive function in middle age: evidence from the Whitehall II study. J Epidemiol Community Health 57: 907-913. settings, in particular long-term trials among healthy adults, are needed to confirm these findings.

\section{Supporting Information}

Table S1 Inclusion-Exclusion. Comparison of characteristics of excluded and included participants, from the original SU.VI.MAX cohort $(\mathrm{N}=13,017)$.

(DOCX)

\section{Acknowledgments}

We thank all scientists, dietitians, technicians and assistants who helped carry out the SU.VI.MAX and SU.VI.MAX 2 studies. We especially thank Stéphane Raffard (neuropsychologist) who was responsible for standardization of the cognitive evaluation, Nathalie Arnault (statistician) who coordinated data management, Frédérique Ferrat who coordinated operational aspects of the neuropsychological evaluation and Gwenaël Monot (computer scientist) who coordinated the computing aspects.

\section{Author Contributions}

Conceived and designed the experiments: EKG PG SH. Performed the experiments: EKG PG SH. Analyzed the data: EKG. Wrote the paper: EKG. Involved in interpreting results and editing the manuscript: EKG HC VAA MT SH PG JMO.

20. Fabrigoule C, Letenneur L, Dartigues JF, Zarrouk M, Commenges D, et al. (1995) Social and leisure activities and risk of dementia: a prospective longitudinal study. J Am Geriatr Soc 43: 485-490.

21. Verghese J, Lipton RB, Katz MJ, Hall CB, Derby CA, et al. (2003) Leisure activities and the risk of dementia in the elderly. N Engl J Med 348: 2508-2516.

22. Verghese J, LeValley A, Derby C, Kuslansky G, Katz M, et al. (2006) Leisure activities and the risk of amnestic mild cognitive impairment in the elderly. Neurology 66: 821-827.

23. Verghese J, Cuiling W, Katz MJ, Sanders A, Lipton RB (2009) Leisure activities and risk of vascular cognitive impairment in older adults. J Geriatr Psychiatry Neurol 22: 110-118.

24. Iwasa H, Yoshida Y, Kai I, Suzuki T, Kim H, et al. (2012) Leisure activities and cognitive function in elderly community-dwelling individuals in Japan: A 5-year prospective cohort study. J Psychosom Res 72: 159-164.

25. Akbaraly TN, Portet F, Fustinoni S, Dartigues JF, Artero S, et al. (2009) Leisure activities and the risk of dementia in the elderly: results from the Three-City Study. Neurology 73: 854-861.

26. Rundek T, Bennett DA (2006) Cognitive leisure activities, but not watching TV, for future brain benefits. Neurology 66: 794-795.

27. Wang HX, Karp A, Winblad B, Fratiglioni L (2002) Late-life engagement in social and leisure activities is associated with a decreased risk of dementia: a longitudinal study from the Kungsholmen project. Am J Epidemiol 155: 10811087.

28. Wang JY, Zhou DH, Li J, Zhang M, Deng J, et al. (2006) Leisure activity and risk of cognitive impairment: the Chongqing aging study. Neurology 66: 911913.

29. Wilson RS, Bennett DA, Bienias JL, Mendes de Leon GF, Morris MC, et al. (2003) Cognitive activity and cognitive decline in a biracial community population. Neurology 61: 812-816.

30. Wilson RS, Bennett DA, Bienias JL, Aggarwal NT, Mendes de Leon CF, et al. (2002) Cognitive activity and incident AD in a population-based sample of older persons. Neurology 59: 1910-1914.

31. Wilson RS, Mendes de Leon CF, Barnes LL, Schneider JA, Bienias JL, et al. (2002) Participation in cognitively stimulating activities and risk of incident Alzheimer disease. JAMA 287: 742-748.

32. Hercberg S, Galan P, Preziosi P, Roussel AM, Arnaud J, et al. (1998) Background and rationale behind the SU.VI.MAX Study, a prevention trial using nutritional doses of a combination of antioxidant vitamins and minerals to reduce cardiovascular diseases and cancers. SUpplementation en VItamines et Mineraux AntioXydants Study. Int J Vitam Nutr Res 68: 3-20.

33. Hercberg S, Galan P, Preziosi P, Bertrais S, Mennen L, et al. (2004) The SU.VI.MAX Study: a randomized, placebo-controlled trial of the health effects of antioxidant vitamins and minerals. Arch Intern Med 164: 2335-2342.

34. Kesse-Guyot E, Fezeu L, Jeandel C, Ferry M, Andreeva V, et al. (2011) French adults' cognitive performance after daily supplementation with antioxidant vitamins and minerals at nutritional doses: a post hoc analysis of the Supplementation in Vitamins and Mineral Antioxidants (SU.VI.MAX) trial. Am J Clin Nutr. 
35. Lezak, M D., Howieson, D B., and Loring, D W. (2004) Neuropsychological Assessment. New York, NY: Oxford University Press.

36. Ivanoiu A, Adam S, Van der LM, Salmon E, Juillerat AC, et al. (2005) Memory evaluation with a new cued recall test in patients with mild cognitive impairment and Alzheimer's disease. J Neurol 252: 47-55.

37. Wechsler D. (1981) Wechsler Adult Intelligence Scale-Revised. New York, NY: Psychological Corporation.

38. Delis DC., Kaplan E., and Kramer JH. (2001) Delis-Kaplan Executive Function System (D-KEFS) examiner's manual. San Antonio, TX: The Psychological Corporation.

39. Vuillemin A, Oppert JM, Guillemin F, Essermeant L, Fontvieille AM, et al. (2000) Self-administered questionnaire compared with interview to assess pastyear physical activity. Med Sci Sports Exerc 32: 1119-1124.

40. Bertrais S, Beyeme-Ondoua JP, Czernichow S, Galan P, Hercberg S, et al. (2005) Sedentary behaviors, physical activity, and metabolic syndrome in middle-aged French subjects. Obes Res 13: 936-944.

41. Kriska AM, Knowler WC, LaPorte RE, Drash AL, Wing RR, et al. (1990) Development of questionnaire to examine relationship of physical activity and diabetes in Pima Indians. Diabetes Care 13: 401-411.

42. Knowler WC, Barrett-Connor E, Fowler SE, Hamman RF, Lachin JM, et al. (2002) Reduction in the incidence of type 2 diabetes with lifestyle intervention or metformin. N Engl J Med 346: 393-403.

43. Pereira MA, FitzerGerald SJ, Gregg EW, Joswiak ML, Ryan WJ, et al. (1997) A collection of Physical Activity Questionnaires for health-related research. Med Sci Sports Exerc 29: S1-205.
44. Ainsworth BE, Haskell WL, Whitt MC, Irwin ML, Swartz AM, et al. (2000) Compendium of physical activities: an update of activity codes and MET intensities. Med Sci Sports Exerc 32: S498-S504.

45. Radloff L (1977) The CES-D Scale: A Self-Report Depression Scale for Research in the General Population. Appl Psychol Meas 1: 385-401.

46. Kesse-Guyot E, Fezeu L, Andreeva VA, Touvier M, Scalbert A, et al. (2012) Total and specific polyphenol intakes in midlife are associated with cognitive function measured 13 years later. J Nutr 142: 76-83.

47. Kesse-Guyot E, Amieva H, Castetbon K, Henegar A, Ferry M, et al. (2011) Adherence to nutritional recommendations and subsequent cognitive performance: findings from the prospective Supplementation with Antioxidant Vitamins and Minerals 2 (SU.VI.MAX 2) study. Am J Clin Nutr 93: 200-210.

48. Tun PA, Lachman ME (2010) The association between computer use and cognition across adulthood: use it so you won't lose it? Psychol Aging 25: 560568.

49. Czaja SJ, Charness N, Fisk AD, Hertzog C, Nair SN, et al. (2006) Factors predicting the use of technology: findings from the Center for Research and Education on Aging and Technology Enhancement (CREATE). Psychol Aging 21: 333-352.

50. Tucker AM, Stern Y (2011) Cognitive reserve in aging. Curr Alzheimer Res 8: 354-360.

51. Clark BK, Sugiyama T, Healy GN, Salmon J, Dunstan DW, et al. (2009) Validity and reliability of measures of television viewing time and other nonoccupational sedentary behaviour of adults: a review. Obes Rev 10: 7-16. 